\title{
Urarina. Identidad y memoria en la cuenca del rio Chambira
}

Brañas, MM, Pérez, CN, Fabiano, E., Villacorta, MD, Schulz, C., Laurie, N.,

Vílchez, JS, Davies, A., Roucoux, KH, Lawson, I., y Andueza, L. (2019).

Instituto de Investigaciones de la Amazonia Peruana, Ministerio del Ambiente, University of St. Andrews, Pontificia Universidad Católica del Perú (Grupo de Antropología Amazonía) y Ministerio de Cultura. Lima: IIAP. 80 pp.

Dentro de la gran variedad de pueblos originarios en el Perú, hay uno sobre el cual se conoce poco: el pueblo Urarina o urarinaaürü, y lo mismo podemos decir de su lengua. Ubicado en territorios de la cuenca del río Chambira tiene actualmente una población de 4,854 personas (INEI, 2017). Información etnográfica y lingüística es difícil de adquirir y un lector espera encontrarlas en tesis de ciencias sociales o en revistas especializadas; sin embargo, la publicación que reseñamos proviene de un organismo del estado: el Instituto de Investigaciones de la Amazonia Peruana (IIAP) en Iquitos. Urarina. Identidad y memoria en la cuenca del río Chambira fue presentado en el Ministerio de Cultura en 2019. Se trata de una pulcra edición, de difusión, pero con un gran valor científico que debiera tener un tiraje mayor pues su información y la documentación fotográfica de gran calidad así lo ameritan.

El pueblo Urarina fue conocido desde tiempos de la colonia por los misioneros jesuitas que crearon una misión por 1763 (Chirif y Mora 1977), se los llamó con el exónimo "shimacu», nombre que identifica también a la familia lingüística Simaco, Además de otros nombres como «itucale» y «cimarrón» (Pozzi- Escot, 1998, p. 160) también se les reconoce la autodenominación kacha edze según el Banco de Pueblos Indígenas del Ministerio de Cultura (https://bdpi.cultura.gob.pe/pueblos/urarina Tomado el 20 de diciembre de 2019). En la página 22, se inserta un interesante comentario sobre el posible origen de la palabra urarina y otras posibles hipótesis.

El libro contiene 7 apartados, además de una breve Presentación e Introducción. El primero, «De las misiones a la extracción petrolera: más de quinientos años de exclusión y olvido» reseña la historia desde la época de la conquista por los espańoles hasta la actualidad donde la explotación de hidrocarburos ha afectado la vida de los pobladores originarios. El punto de partida es el Informe presentado por el Padre Figueroa acerca de las misiones jesuíticas en el Marańón. El objetivo de los misioneros era llevar a cabo una Reducción que consideraba "cómoda», hecho que no llega a concretarse hasta mucho después en el siglo XVIII. Por esos años, hubo contacto interétnico con los itucales y de ahí probablemente que se les haya identificado como tales. Los misioneros se trasladan y con ellos los reducidos. Al ser expulsados de América, los jesuitas dejarían su misión para ser reemplazados años después por los franciscanos. Previamente, muchos urarina habían abandonado la misión o se habían internado en el monte. 
Un siglo después, una nueva amenaza surge contra este pueblo. Se trata de la explotación del caucho que arrasó con la libertad y la vida de muchos pueblos amazónicos, entre ellos los urarina. Ellos son expoliados, llevados en calidad de esclavos por los patrones caucheros que se instalan en la cuenca del Chambira. Fueron obligados a trabajos forzados con el fin de recaudar cuotas diarias de caucho de los árboles gomeros. Nuevas instituciones económicas les son impuestas como el sistema de habilitación y el enganche. Esta época tristemente recordada como el «boom del caucho», diezmó gran parte de la población amazónica hasta la primera parte del siglo veinte. En esta sección se da cuenta de posteriores actividades extractivas que no han beneficiado en modo alguno a la población urarina. Los misioneros evangelistas suceden a los católicos «introduciendo nuevos sistemas de valores que han sido muy dañinos para el pueblo urarina, ya que, en algunos casos, fortalecieron el modo patronal existente (Fabiano, 2018)».

La segunda sección se denomina «Organización social y dinámicas económicas». Los autores sostienen que falta documentación para poder describir «las dinámicas de cambio experimentadas desde los primeros contactos con los europeos». Sin embargo, se señala que después de la tenebrosa experiencia con los barones caucheros, la población se aleja y se mantiene aislada, ubicándose en las zonas interfluviales del Chambira. Sin embargo, esta estrategia ya no pudo mantenerse frente al avance de agentes externos a fines del siglo XX. En la actualidad, la organización del pueblo urarina se mantiene fiel a la estructura política tradicional basada en el sistema de parentesco, sin seguir estrictamente la figura de Asamblea General dada en la Ley de Comunidades Nativas.

La tercera sección «Las mujeres y la memoria del tejido en el pueblo urarina»es quizás la más documentada del libro pues da cuenta del arte del tejido de las mujeres hechos con la fibra del aguaje (Mauritua flexuosa). Recientemente, los tejidos del Pueblo Urarina han obtenido el reconocimiento de patrimonio cultural de la Nación. El nombre de la cuenca, Chambira, nos indica que ese recurso natural abunda en la zona. Las mujeres manejan el arte tradicional del tejido empleando la fibra del aguaje y de la chambira (Astrocarynn chambira). Tejen hamacas que originalmente solo eran para los recién nacidos, pero ahora también la hacen más grandes debido a su aceptación en el mercado. Además, confeccionan bolsos de red o shicras y otros objetos utilitarios. También han usado el algodón vegetal (Gossypium sp.). Su uso es sustentado por una serie de fuentes bibliográficas que son mencionadas. Los colores son tomados de tintes vegetales o de tierra. Se describe en detalle el uso de taller de cintura que es considerada una técnica prehispánica. Los paños o esteras se denominan ela y en castellano cachihuango que en verdad es un quechuismo.

La cuarta sección está dedicada a la espiritualidad y a la tradición oral y tiene que ver con el origen mítico del tejido que les fuera entregada por kaludi, un ave que adquirió forma humana para ayudar a una anciana a la que su yerno le cortara los dedos por no saber tejer. Esta información se complemente con una descripción de la sociedad 
urarina, especialmente la referida a las mujeres, desde su menarquía (ichaumenaniia) hasta su adultez. El tejido tradicional ela sirve de mortaja a los difuntos. Se describe el rol de los cantos o aaü que las abuelas enseńan a las niñas para prevenir los daños o enfermedades.

El quinto apartado "Alaa, la palmera de los urarinaaüü» habla de la importancia del ecosistema de humedales que han sido aprovechados de manera eficiente y sostenible por los urarina. La riqueza biológica que se acumula aquí permite la abundancia de la palmera del aguaje (Mauritua flexuosa) proporcionando la materia prima para los tejidos. El aguaje alaa tiene múltiples usos como alimento y también contribuye eficientemente a la economía de los pobladores. La fauna de la selva también se nutre del aguaje. Por su valor, cuidadosamente descrito en esta sección, se recomienda un manejo de este recurso para protegerlo de la depredación.

Como era de esperarse estos parajes tienen sus dueños protectores, uno de ellos es el baainu que interactúa con el pueblo urarina y que adopta cualquier forma; si lo hace como animal su preferencia va por el mono blanco, negro o sachavaca. En su casa hay un tigre prisionero que actúa como guardián. El badinu cuando se presenta en forma humana lleva un mono en sus hombros o un ave. Habita en los dos ecosistemas principilaes el jiri y Alaka. El primero se caracteriza por encontrarse en terreno inundado y donde abunda el aguaje con variadas especies animales y vegetales; dentro de los parámetros occidentales se lo considera como un pantano abierto y es de difícil acceso. En el Alaka, se puede encontrar "poblaciones densas de aguaje» que comparten con especies vegetales grandes. El jiri y Alaka son fundamentales para la sobrevivencia del pueblo uranina pues allí encuentran los animales para su alimentación y los materiales para la construcción de artefactos utilitarios. Su conocimiento de estos dos ecosistemas y el manejo que le dan son de gran valor para la ciencia. El aguaje los vincula con su pasado porque les ha permitido mantener técnicas antiguas y comprender los fenómenos actuales del cambio climático.

El texto culmina con dos apartados más que describen la importancia de estos humedales en la construcción de la identidad urarina y cómo este pueblo ha construido formas de vida y de arte que son poco conocidas. Hoy en día, las destrezas y habilidades de este pueblo son descritas a través de publicaciones estatales como la que hemos reseñado pues ya no son material exclusivo de cronistas, antropólogos o lingüistas. En este sentido, el IIAP ha conseguido combinar la información científica con el pensamiento indígena, en textos sencillos con una diagramación y fotografía que revela el gran respeto por el pueblo urarina. Esperamos que vengan más textos de esta calidad. 


\section{Referencias}

Chirif. A.; Mora, C. (1997). Atlas de comunidades nativas (SINAMOS). Lima, Perú: Ministerio de Guerra.

Pozzi-Escot, I. (1988). Lengua urarina. En I., Pozzi-Escot, Ed., El multilingüismo en el Perú, (158-161). Cusco: Centro de Estudios Regionales Andinos Bartolomé de Las Casas.

María Chavarría Mendoza

Universidad Nacional Mayor de San Marcos

chava001@yahoo.com 